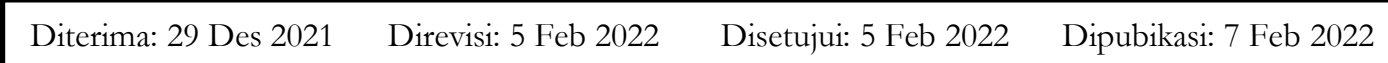

\title{
PERBANDINGAN KEBUTUHAN MODAL KERJA
}

\author{
Wawan Devis Wahyu ${ }^{1 *}$, Dafiar Syarif2), Rezki Agrisa Ditama ${ }^{3)}$, Mursal $^{4)}$ \\ ${ }^{1234}$ Fakultas Ekonomi dan Bisnis Islam IAIN Kerinci, Sungai Penuh, Indonesia \\ *Koresponden Email11): w2nwahyu@gmail.com \\ Email2): dafiarsyarif24@gmail.com \\ Email3): rezkiaditama8116@gmail.com \\ Email ${ }^{4)}$ : mursalbesty@gmail.com
}

\begin{abstract}
Abstrak
Penelitian ini bertujuan melihat perbandingan kebutuban modal kerja pada PDAM Tirta Mayang Kota Jambi dan PD AM Tirta Sakti Kabupaten Kerinci tahun 2013-2017. Penelitian tersebut dilakukan di Kota Jambi dan Kabupaten Kerinci. Penelitian ini menggunakan Teknik analisis deskriptif statistik dan Independent Sample TTest. Hasil penelitiannya memperlihatkean bahwa nilai signifikansi untuk equal variance assumed sebesar 0,059 > 0,05 yang berarti tidak terdapat perbedaan yang tidak signifikan kebutuban modal kerja antara PDAM Tirta Mayang Kota Jambi dan PD AM Tirta Sakti Kabupaten Kerinci. Besaran kebutuhan modal kerja untuk PDAM Kota Jambi jauh lebih besar dibandingkan PD AM Kabupaten Kerinci pada periode 2013-2017 dimana rata-rata kebutuhan modal kerja untuk PDAM Kota jambi adalah sebesar Rp23.661.204.073,25 dan Rp7.568.176.762,16 untuk PDAM Kabupaten Kerinci. Kesimpulan menunjukkan bahwa tidak terdapat perbedaan kebutuhan modal kerja antara PD AM Tirta Mayang Kota Jambi dan PD AM Tirta Sakti Kabupaten Kerinci ataupun perusahaan PD AM Tirta Mayang Kota Jambi.
\end{abstract}

Kata Kunci: Perputaran Modal Kerja, Kebutuban Modal Kerja

\section{COMPARISON OF WORKING CAPITAL REQUIREMENTS}

\begin{abstract}
This study aims to compare the working capital requirements of PDAM Tirta Mayang, Jambi City and PDAM Tirta Sakti, Kerinci Regency in 2013-2017. The research was conducted in Jambi City and Kerinci Regency. This study uses descriptive statistical analysis techniques and Independent Sample T-Test. The results of the research show that the significance value for equal variance assumed is $0.059>0.05$, which means that there is no insignificant difference in working capital requirements between PDAM Tirta Mayang, Jambi City and PDAM Tirta Sakti, Kerinci Regency. The amount of working capital requirement for PDAM Kota Jambi is much larger than PDAM Kabupaten Kerinci in the period 2013-2017 where the average working capital requirement for PDAM Kota Jambi is Rp.23,661,204,073.25 and Rp.7,568,176,762.16 for PDAM Kabupaten Kerinci. The conclusion shows that there is no difference in working capital requirements between PDAM Tirta Mayang in Jambi City and PDAM Tirta Sakti in Kerinci Regency or PDAM Tirta Mayang in Jambi City.
\end{abstract}

Keywords: Working Capital Turnover, Working Capital Requirement

\section{PENDAHULUAN}

PDAM adalah unsur usaha yang melakukan dua kapasitas, yaitu "Social Oriented" (sangat mendukung air bersih) dan "Profit Oriented" (berarti menciptakan manfaat untuk bekerja dalam latihan dan sumber pendapatan daerah). Bagaimanapun juga, substansi dari Organisasi Penyediaan Air Teritorial adalah organisasi yang terletak secara sosial. Organisasi 
FINANCE: a Research Journal on Islamic Finance Vol.07 No. 02 Desember 2021 http//jurnal.radenfatah.ac.id/index.php/i-finance

Wawan, Dafiar, Rezki dan Mursal.........Perbandingan Kebutuhan Modal Kerja

yang diatur secara sosial pada umumnya tidak bermaksud mencari keuntungan semata, tetapi lebih banyak bantuan yang terletak di daerah setempat. Manfaat merupakan prasyarat ketahanan bagi organisasi. (Andries 2011)

Sebagai aturan, sebuah organisasi didirikan untuk mewujudkan beberapa tujuan. Tujuan organisasi bisa berupa manfaat yang setinggi-tingginya dan menjamin ketahanan organisasi. Untuk mendirikan sebuah organisasi, diperlukan modal yang cukup, karena seandainya tidak ada aset yang dapat diakses, organisasi tidak dapat mendukung kegiatannya. Modal kerja sangat penting dalam menyelesaikan latihan bisnis. Setiap organisasi sangat membutuhkan modal kerja dalam melakukan latihan fungsional seharihari. Untuk membantu setiap gerakan dalam suatu organisasi, tentunya diperlukan modal kerja yang memadai, baik dari segi kualitas maupun jumlah. Dengan modal kerja yang cukup dan besar, organisasi tidak akan kesulitan dalam mengelola keadaan darurat moneter atau masalah moneter, sehingga organisasi dapat bekerja dengan baik dan ideal sehingga tujuan organisasi dapat tercapai. Pengertian modal kerja yang menyertainya seperti yang ditunjukkan oleh (Kasmir 2016) adalah "Modal yang dimanfaatkan untuk melakukan tugastugas organisasi". Modal kerja juga bisa diartikan sebagai spekulasi yang menempatkan sumber daya ke dalam sumber daya saat ini atau sumber daya sesaat seperti uang, perlindungan, piutang, persediaan dan sumber daya lainnya saat ini. Sedangkan menurut (Fahmi 2014) Modal kerja adalah kepentingan organisasi dalam sumber daya sementara kas, proteksi, persediaan dan catatan piutang. Ukuran modal bergantung pada ukuran organisasi juga. Untuk mengetahui besarnya modal suatu organisasi, kita dapat mengetahui dari laporan fiskalnya, khususnya catatan moneter. Dari laporan aset, kita juga dapat melihat bahwa apa yang dicatat dekat dengan biaya laporan aset menunjukkan modal sesuai dengan bentuknya dan apa yang terletak dekat dengan kredit catatan moneter menunjukkan modal seperti yang ditunjukkan oleh sumbernya. Modal yang menunjukkan strukturnya disebut modal dinamis, sedangkan modal yang memperlihatkan sumbernya disebut sebagai modal menyendiri. Ringkasan anggaran pada dasarnya adalah hasil dari interaksi pembukuan yang siap sesuai aturan akuntansi yang tepat yang dapat digunakan untuk menyampaikan informasi keuangan kepada individu yang diinvestasikan sehingga mereka tidak tercampur dalam menggunakan data ini. Unsur-unsur yang mempengaruhi seberapa besar kebutuhan modal kerja dalam suatu organisasi adalah: (1) sifat atau jenis organisasi. (2) Waktu yang dibutuhkan untuk mengirimkan atau mendapatkan produk yang akan dijual dan biaya per unit barang dagangan. (3) Persyaratan perolehan zat yang tidak dimurnikan. (4) Persyaratan penawaran. (5) Tingkat perputaran saham.

Modal kerja diharapkan untuk mendanai latihan fundamental organisasi, berbeda dengan modal tetap, sehingga modal kerja lebih mudah beradaptasi, berapa banyak modal kerja yang lebih mudah untuk ditambah atau dikurangi yang ditunjukkan dengan persyaratan dan komponen modal kerja tidak sulit untuk diubah. Modal kerja sangat dinamis dalam organisasi selama organisasi menyelesaikan latihannya. Modal kerja dapat dipisahkan menjadi modal kerja kotor dan modal kerja bersih. Modal kerja kotor menggabungkan setiap sumber daya saat ini, sedangkan modal kerja bersih adalah perbedaan antara sumber daya saat ini dan kewajiban lancar. Ada dua jenis kelompok modal kerja: (1) Permanent Working Capital ialah modal kerja yang harus selalu ada dalam organisasi sehingga organisasi dapat melakukan latihannya untuk mengatasi masalah pelanggan, (2) Variable Working Capital ialah modal kerja yang jumlahnya berubah sesuai dengan perubahan latihan atau kondisi yang berbeda yang mempengaruhi organisasi. 
FINANCE: a Research Journal on Islamic Finance Vol.07 No. 02 Desember 2021 http//jurnal.radenfatah.ac.id/index.php/i-finance Wawan, Dafiar, Rezki dan Mursal.........Perbandingan Kebutuhan Modal Kerja

Fenomena yang terjadi di Provinsi Jambi dari tahun ketahun tentang pelayanan yang diberikan oleh PDAM selalu menuai kritik ataupun keluhan dari masyarakat. Oleh karena itu, PDAM Tirta Sakti Kabupaten Kerinci dan PDAM Tirta Mayang Kota Jambi harus bekerja pada diri mereka sendiri dalam menghadapi kesulitan menawarkan jenis bantuan dan dapat memajukan posisi moneter mereka dengan alasan bahwa peningkatan posisi moneter menyiratkan bahwa pembayaran untuk administrasi yang dikelola negara bagian akan meningkat. Petunjuk dalam pelaksanaan moneter dibuat untuk memiliki opsi untuk memecah berbagai latihan moneter yang berlaku untuk mengevaluasi tingkat pencapaian keuangan organisasi. Pada umumnya, evaluasi pelaksanaan moneter mencakup perkiraan keseimbangan desain modal, penguatan sumber daya yang ditanamkan, kemampuan dalam menangani aset dan pemanfaatan aset serta kemampuan untuk membayar komitmen yang berkembang. Selain itu, juga dapat dilihat tingkat produktivitas pelaksanaan moneter dalam semua kegiatan organisasi dan kemampuan organisasi untuk menciptakan manfaat.

\section{Tabel 1}

Data Perkembangan Laba (Rugi) Periode 2013-2017

\begin{tabular}{rrrr}
\hline No & Tahun & \multicolumn{2}{c}{ Laba (Rugi) } \\
\cline { 3 - 4 } & & $\begin{array}{c}\text { PDAM Tirta Mayang Kota } \\
\text { Jambi }\end{array}$ & $\begin{array}{c}\text { PDAM Tirta Sakti Kab. } \\
\text { Kerinci }\end{array}$ \\
\hline $\mathbf{1}$ & 2013 & 210.586 .777 & $(826.640 .322)$ \\
\hline $\mathbf{2}$ & 2014 & $(336.049 .649)$ & $(1.226 .206 .067 .692,75)$ \\
\hline $\mathbf{3}$ & 2015 & 1.757 .785 .221 & 480.508 .048 \\
\hline $\mathbf{4}$ & 2016 & $(2.107 .105 .467)$ & $454.818 .808,83$ \\
\hline $\mathbf{5}$ & 2017 & $878.919 .808,64$ & \\
\hline
\end{tabular}

Sumber : Data dari Laporan Keuangan Tahun 2017

Berdasarkan data dari laporan keuangan 2017 dapat kita lihat pada tahun 2013 PDAM Kota Jambi memperoleh keutungan sebesar Rp 210.586.777, sedangkan PDAM Kabupaten Kerinci mengalami kerugian sebesar Rp 826.640.322. Pada tahun 2014 PDAM Kota Jambi merugi sebesar RP 336.049.649 dan PDAM Kabupaten Kerinci masih tetap mengalami kerugian sebesar Rp 589.206.024,75. Pada tahun 2015 PDAM Kota Jambi kembali memperoleh keuntungan sebesar Rp 1.757.785.221, sedangkan PDAM Kabupaten Kerinci masih tetap mengalami kerugian sebesar Rp 1.226.667.692,14. Pada tahun 2016 PDAM Kota Jambi kembali mengalami kerugian sebesar Rp 2.107.105.467, sedangkan PDAM Kabupaten Kerinci berhasil memperoleh keuntungan sebesar Rp 480.508.048. pada tahun 2017 PDAM Kota Jambi kembali memperoleh keuntungan sebesar Rp878.919.808,64, sedangkan PDAM Kabupaten Kerinci juga memperoleh keuntungan sebesar Rp454.818.808,83.

Laporan keuangan PDAM Kota Jambi tersebut menunjukkan selama lima tahun terakhir PDAM rata-rata memperoleh laba lebih besar dibandingkan kerugiannya namun tidak seperti PDAM Kabupaten Kerinci, yang hampir mengalami kerugian dalam lima tahun terakhir kecuali pada tahun 2016 dan 2017 yang berhasil meningkatkan kinerja keuangannya dan memperoleh laba. Dilihat dari Laporan Laba (Rugi), perusahaan milik daerah ini malah menjadi beban pemerintah daerah terutama Kabupaten Kerinci. Meskipun demikian, menurut Surat Kepmen Dalam Negeri No: 690-069 Tahun 1992 tentang Contoh Peraturan Khusus PDAM Pengurus yang menerangkan bahwa PDAM memiliki tugas 
FINANCE: a Research Journal on Islamic Finance Vol.07 No. 02 Desember 2021 http//jurnal.radenfatah.ac.id/index.php/i-finance

Wawan, Dafiar, Rezki dan Mursal.........Perbandingan Kebutuhan Modal Kerja

pokok memberikan jenis bantuan umum kepada daerah, dimana dalam melaksanakan kapasitasnya PDAM diandalkan atas memiliki pilihan untuk mendukung diri mereka sendiri (pembiayaan sendiri) dan harus berusaha untuk mendorong tingkat bantuan publik. Demikian pula, PDAM juga diharapkan memiliki opsi untuk menambah kemajuan Pemda. Capital working yang menjalankan fungsi operasi dalam suatu bisnis bisa dibagi menjadi sebagian klasifikasi. macam-macam Capital working yaitu : Permanent Working Capital, modal kerja ini harus selalu ada ataupun diperluksn perusahaan agar selalu bisa melakukan fungsinya, Permanent Working Capital dibedakan menjadi Primary working capital dan normal working capital. Capital working minimum yang mestinya ada pada perusahaan dalam menjamin keberlangsungan kegiatan usahanya disebut juga dengan Primary working capital dan normal working capital merupakan total modal kerja yang ada untuk melaksanakan produksi normal. Dan yang kedua V ariable Working Capital, yakni modal yang berubah-ubah tergantung keadaan. V ariable Working Capital dibedakan menjadi cyclical working capital yakni modal yang berubah-ubah dikarenakan fluktuasi konjungtur dan emergency working capital yang merupakan modal yang jumlahnya berubah-ubah disebabkan keadaan darurat tanpa diketahui sebelumnya.

Komponen modal kerja pada umumnya terdiri dari uang, proteksi yang menarik, persediaan, piutang, dan uang muka. Agar latihan tetap berlangsung dengan baik, komponen-komponen pada modal kerja harus diawasi dengan baik. Berapa banyak modal kerja yang dibutuhkan oleh setiap organisasi berfluktuasi, sesuai dengan ukuran organisasi dan jenis gerakan organisasi yang bersangkutan. Dengan cara ini organisasi harus memberikan modal kerja yang memadai, baik dalam jumlah maupun struktur. Dengan ukuran modal kerja yang memadai, organisasi akan benar-benar ingin bekerja secara moneter, terlebih lagi organisasi akan benar-benar ingin membatasi kesulitan keuangan dalam mengelola kebutuhan modal kerja dan akan menjaga organisasi dari menghadapi kemalangan. Berdasarkan gambaran di atas, maka perincian permasalahan dalam tinjauan ini adalah berapa modal kerja yang dibutuhkan PDAM Tirta Mayang Jambi dan Tirta Sakti Kab. Kerinci periode 2013-2017.

Jika bisnis diaktifkan hanya sekali, kebutuhan capital working pada produksi modal kerja saat periode konversi akan tercukupi. Namun, untuk perusahaan yang umumnya didirikan untuk beroperasi secara berkelanjutan, kebutuhan modal kerja adalah jumlah uang tunai yang dikeluarkan setiap hari dikalikan dengan waktu pemrosesan modal kerja.

Penelitian Terdahulu yang diperoleh peneliti sebagai yaitu (Suryani 2016) yang meneliti tentang kecukupan dan prasyarat modal kerja pada PDAM Tirta Mayang Jambi, didapatkan hasil bahwa kebutuhan modal yang berfungsi bervariasi yang secara umum akan meningkat dimana pada tahun 2010 kenaikan paling berkurang adalah 106,07\% dan pada tahun 2013 kenaikan paling tinggi adalah 208,03\%, dengan normal sebesar 126,33\%, kemudian pada saat itu secara umum akan mengalami kenaikan dan penurunan dimana pada tahun 2011 mengalami penurunan paling kecil sebesar 81,06\% dan pada tahun 2013 mengalami kenaikan yang cukup signifikan sebesar $117,2 \%$, dengan normal sebesar $83,06 \%$. Sedangkan, pada penelitian perbandingan kebutuhan modal kerja pada PDAM Tirta Mayang Jambi dengan PDAM tirta sakti Kab. Kerinci pada tahun 2018 didapatkan hasil dimana di tahun 2014 mengalami peningkatan tertinggi sebesar 28,11\% dan pada tahun 2017 mengalami penurunan sebesar 14,54\%, dengan rata-rata sebesar 8,18\%. Dan untuk Kebutuhan modal kerja PDAM Tirta Sakti Kabupaten Kerinci juga mengalami fluktuasi 
FINANCE: a Research Journal on Islamic Finance Vol.07 No. 02 Desember 2021 http//jurnal.radenfatah.ac.id/index.php/i-finance

Wawan, Dafiar, Rezki dan Mursal.........Perbandingan Kebutuhan Modal Kerja

yang memiliki kecenderung meningkat dimana pada tahun 2017 mengalami peningkatan tertinggi sebesar 103,49\% dan pada tahun 2014 turun sebesar 2,04\%, dengan rata-rata sebesar 24,10\%. Besaran kebutuhan modal kerja untuk PDAM Kota Jambi jauh lebih besar dibandingkan PDAM Kabupaten Kerinci pada periode 2013-2017 dimana rata-rata kebutuhan modal kerja untuk PDAM Kota jambi adalah sebesar Rp23.661.204.073,25 dan Rp7.568.176.762,16 untuk PDAM Kabupaten Kerinci.

Riset (Hakim and Mulyani 2017) juga meneliti tentang "Analisis kebutuhan modal kerja di rumah makan bintang lima di Samarinda" hasilnya Kecepatan perputaran modal kerja tahun 2016 sebesar 1,26 kali sedangkan untuk tahun 2017 kecepatan perputaran modal kerja sebesar 1,67 kali. kebutuhan modal kerja di rumah makan Bintang Samarinda pada tahun 2016 tidak perlu dipusingkan dengan kebutuhan modal kerja tambahan karena saat ini sudah melimpah (dari modal kerja yang tersedia singkat setelah pemeriksaan) sebesar Rp 43.381.285.715 dan selanjutnya untuk tahun 2017 juga tidak ada kebutuhan untuk tambahan modal kerja, mengingat prasyarat modal kerja telah melampaui $\mathrm{Rp}$ 235.118.802.395 sehingga dapat menjamin kelancaran aktivitas kafe Bintang di Samarinda. Selanjutnya kebutuhan modal kerja dalam tinjauan ini dipengaruhi oleh kecepatan penyebaran uang tunai dalam melakukan latihan bisnisnya dan latihan bisnis lainnya yang diselesaikan di rumah makan Bintang Samarinda, sehingga sedikit bahaya yang mungkin terjadi, tidak ada kekurangan kebutuhan modal kerja, pemanfaatan uang secara efektif. Spekulasi yang dikemukakan oleh sang pencipta memang benar dan bisa diakui. Penelitin ini berbanding terbalik dengan kondisi kecukupan modal kerja PDAM Tirta Mayang Kota Jambi dan PDAM Tirta Sakti Kabupaten Kerinci yang masih belum efesien. Dan juga Penelitian (Murniati 2016) yang berjudul "analisis kebutuhan modal kerja pada cv. bintang timur jaya di makassar" yang menunjukkan hasil bahwa Kebutuhan modal kerja tergantung dari hasil pemeriksaan adalah Rp. 64.043.539.00. Ada perbedaan kritis, yaitu Rp. 50.105.102.00. Hal ini menunjukkan bahwa modal kerja yang dapat diakses telah memiliki pilihan untuk memenuhi kebutuhan modal yang berfungsi untuk menjamin kelancaran kegiatan di tahun 2015. Rendahnya tingkat perputaran modal kerja absolut yang terdiri dari uang (bank), piutang dan persediaan, yaitu 4,69 kali, menyebabkan kebutuhan modal kerja menjadi sangat besar. Tingkat perputaran yang kecil ini menyebabkan modal kerja yang terbatas untuk waktu yang cukup lama diubah lagi menjadi uang tunai sehingga tidak akan ada cukup modal kerja yang tersedia untuk digunakan dengan cepat dalam siklus bisnis atau latihan organisasi. Terlebih lagi sedikitnya kecepatan perputaran piutang sebanyak 4,69 kali dalam setahun (365 hari) dan lamanya kecepatan pengembalian piutang menjadi uang membuat kebutuhan modal kerja semakin tinggi, mengingat piutang membutuhkan 77,83 hari untuk mendapatkan kembali uang tunai.

Masalah yang akan dikaji dalam penelitian ini adalah bagaimana perbandingan kebutuhan modal berfungsinya PDAM Tirta Mayang Kota Jambi dan PDAM Tirta Sakti Kabupaten Kerinci periode 2013-2017?

Riset ini bertujuan guna melihat perbandingan kebutuhan modal kerja di PDAM Tirta Mayang Kota Jambi dan PDAM Tirta Sakti Kabupaten Kerinci periode 2013-2017.

\section{METODE PENELITIAN}

\section{Tempat Penelitian}

Penelitian ini dilaksanakan di PDAM Tirta Mayang Kota Jambi dan PDAM Tirta Sakti Kabupaten Kerinci periode 2013-2017. 
FINANCE: a Research Journal on Islamic Finance Vol.07 No. 02 Desember 2021 http//jurnal.radenfatah.ac.id/index.php/i-finance

Wawan, Dafiar, Rezki dan Mursal .Perbandingan Kebutuhan Modal Kerja

\section{Definisi Operasional Variabel}

Pengukuran variabel dalam penelitian ini dapat di jelaskan sebagai berikut:

1. Analisis Perputaran Modal Kerja

a. Perputaran Kas

Rasio Perputaran Kas adalah rasio yang membandingkan antara penjualan dan ratarata kas.

b. Perputaran Piutang

Rasio Perputaran Piutang merupakan rasio yang membandingkan penjualan dan ratarata piutang

c. Perputaran Persediaan

Rasio Perputaran Persediaan merupakan rasio yang membandingkan antara penjualan dan rata-rata persedian.

2. Kebutuhan Modal Kerja

Rasio kebutuhan modal kerja $=$ Penjualan $/$ Total kecepatan perputaran modal kerja

\section{Teknik Analisis Data}

\section{Analisis Deskriptif}

Metode analisis deskriptif merupakan ukuran yang digunakan untuk memecah informasi dengan menggambarkan atau menggambarkan informasi yang telah dikumpulkan untuk apa nilainya tanpa bermaksud menyebabkan tujuan yang berlaku untuk populasi umum atau spekulasi (Sugiyono 2013).

\section{Uji Normalitas dan Uji Homogenitas}

Jika analisis menggunakan metode parametrik, maka persyaratan normalitas harus terpenuhi yaitu data berasal dari distribusi yang normal (Sugiyono 2013). sedangkan, Uji Homogenitas adalah uji menyatakan salah satu persyaratan pengambilan sampel adalah sampel tersebut harus representatif, artinya mewakili populasi. Apabila populasinya sama maka sampel juga memiliki karakteristik sama dan tidak terdapat variansi diantara kelompok sampel satu dengan yang lain.

\section{Uji Independent Sample T-Test}

Untuk mengetahui perbandingan kebutuhan modal kerja yang terpada PDAM Tirta Mayang Jambi dan PDAM Tirta Sakti Kerinci digunakan uji independent sample t-test dengan dasar pengambilan keputusan sebagai berikut:

Ho diterima jika probabilitas (sig) $>0,05$ artinya tidak terdapat perbedaan

Ha diterima jika probabilitas $(\mathrm{sig})<0,05$ artinya terdapat perbedaan

\section{HASIL PENELITIAN DAN PEMBAHASAN}

\section{Perhitungan Analisis Kebutuhan Modal Kerja pada PDAM Tirta Mayang Kota Jambi Periode Tahun 2013-2017}

\section{Analisis Perputaran Modal Kerja}

Modal kerja terus bekerja atau berputar di dalam organisasi selama organisasi yang bersangkutan baik untuk dijalankan. Periode perputaran modal yang berfungsi dimulai dari saat uang dimasukkan ke dalam bagian-bagian modal kerja sampai pada saat kembali menjadi uang tunai.

Semakin terbatas periode berarti semakin cepat pivot atau semakin tinggi tingkat turnover. Berapa lama periode perputaran modal yang berfungsi bergantung pada berapa 
FINANCE: a Research Journal on Islamic Finance Vol.07 No. 02 Desember 2021 http//jurnal.radenfatah.ac.id/index.php/i-finance

Wawan, Dafiar, Rezki dan Mursal.........Perbandingan Kebutuhan Modal Kerja

lama waktu perputaran dari setiap bagian dari modal yang berfungsi. Perputaran kas, perputaran piutang, perputaran stok dan perputaran modal kerja harus terlihat pada tabel terlampir.

\section{Tabel 2}

Penjualan Air, Kas, Piutang, Persediaan PDAM Tirta Mayang Kota Jambi (Rp 1.000)

\begin{tabular}{|c|c|c|c|c|c|}
\hline & 2013 & 2014 & 2015 & 2016 & 2017 \\
\hline Penjualan Air & 54.862 .430 & 61.356 .784 & 69.658 .179 & 71.247 .006 & 72.834 .206 \\
\hline Kas dan Setara Kas & 4.557 .996 & 5.700 .364 & 6.619 .586 & 5.105 .401 & 4.517 .408 \\
\hline Piutang & 6.982 .104 & 7.246 .528 & 8.740 .897 & 6.850 .791 & 8.932 .064 \\
\hline Persediaan & 10.957 .884 & 15.885 .975 & 13.500 .130 & 24.812 .089 & 23.567 .068 \\
\hline
\end{tabular}

Sumber : Penelitian lapangan Data diolah, 2022

Berdasarkan tabel 2. dapat dihitung Perputaran Capital Working PDAM Tirta Mayang Jambi dengan hasil perhitungan dari cash turnover, receivable turnover, inventory turnover, dan capital working turnover bisa dilihat di tabel berikut:

Tabel 3.

Kebutuhan Modal Kerja PDAM Tirta Mayang Kota Jambi

\begin{tabular}{ccccc}
\hline Tahun & $\begin{array}{c}\text { Perputaran } \\
\text { Kas } \\
\text { (hari) }\end{array}$ & $\begin{array}{c}\text { Perputaran } \\
\text { Piutang } \\
\text { (hari) }\end{array}$ & $\begin{array}{c}\text { Perputaran } \\
\text { Persediaan } \\
\text { (hari) }\end{array}$ & $\begin{array}{c}\text { Total Kecepatan } \\
\text { Perputaran Modal Kerja } \\
\text { (kali) }\end{array}$ \\
\hline 2013 & 29,90 & 45,80 & 72 & 2,44 \\
\hline 2014 & 33,46 & 42,50 & 93,26 & 2,13 \\
\hline 2015 & 34,22 & 45,17 & 69,76 & 2,41 \\
\hline 2016 & 25,80 & 34,65 & 125,43 & 1,94 \\
\hline 2017 & 22,33 & 19,43 & 116,50 & 2,27 \\
\hline $\begin{array}{c}\text { Rata- } \\
\text { rata }\end{array}$ & $\mathbf{2 9 , 1 4}$ & $\mathbf{3 7 , 5 1}$ & $\mathbf{9 5 , 3 9}$ & $\mathbf{2 , 2 4}$ \\
\hline
\end{tabular}

Sumber : Penelitian lapangan Data diolah, 2022

Terlihat dari tabel di atas bahwa perputaran kas, piutang, persediaan dan modal kerja selama PDAM Tirta Mayang Jambi berubah. Perputaran uang normal adalah 29,14 hari, perputaran piutang normal adalah 37,51 hari, perputaran persediaan normal adalah 95,39 hari dan perputaran modal kerja lengkap adalah 2,24 kali. Perputaran uang terlama pada tahun 2015 adalah 34,22 hari dan tercepat pada tahun 2017 adalah 22,33 hari. Perputaran piutang terlama pada tahun 2013 adalah 45,80 hari dan tercepat pada tahun 2017 adalah 19,43 hari. Perputaran saham terlama pada tahun 2016 adalah 125,43 hari dan tercepat pada tahun 2015 adalah 69,76 hari. Perputaran modal kerja absolut yang paling menonjol terjadi pada tahun 2013 sebanyak 2,44 kali dan terendah pada tahun 2016 sebesar 1,94 kali.

\section{Analisis Kebutuhan Modal Kerja}

Sangat penting modal kerja bagi organisasi karena organisasi yang tidak mempunyai modal kerja yang memadai akan merasa sulit untuk melakukan latihannya, atau aktivitasnya akan melambat. Tanpa modal kerja yang memadai, sebuah organisasi akan kehilangan kesempatan untuk membangun jumlah dan sifat item yang dibuat. Dengan asumsi itu terjadi, dia akan ditinggalkan oleh kliennya, dan menanggung kemalangan. Dengan cara ini, sebagian besar uang yang dibuat oleh pengawas keuangan didedikasikan untuk tugas seharihari organisasi. Seberapa besar modal kerja bergantung pada jenis bisnisnya, namun secara 
FINANCE: a Research Journal on Islamic Finance Vol.07 No. 02 Desember 2021 http//jurnal.radenfatah.ac.id/index.php/i-finance

Wawan, Dafiar, Rezki dan Mursal.........Perbandingan Kebutuhan Modal Kerja

keseluruhan nilai modal yang berfungsi suatu organisasi lebih dari setengah dari semua sumber daya, sehingga memerlukan administrasi yang signifikan.

Table 4

Penjualan Air, Kas, Piutang, dan Persediaan (Rp)

\begin{tabular}{lccccc}
\hline & $\mathbf{2 0 1 3}$ & $\mathbf{2 0 1 4}$ & $\mathbf{2 0 1 5}$ & $\mathbf{2 0 1 6}$ & $\mathbf{2 0 1 7}$ \\
\hline Penjualan Air & 54.862 .430 .120 & 61.356 .783 .650 & 69.658 .178 .831 & 71.247 .006 .440 & 72.834 .205 .583 \\
\hline $\begin{array}{l}\text { Total } \\
\text { Kecepatan }\end{array}$ & 2,44 & 2,13 & 2,41 & & \\
$\begin{array}{l}\text { Perputaran } \\
\text { Modal kerja }\end{array}$ & & & & & \\
\hline
\end{tabular}

Sumber : Penelitian lapangan Data diolah, 2022

Berdasarkan tabel 4. dapat dihitung Kebutuhan Modal Kerja PDAM Tirta Mayang Kota Jambi sebagaimana yang dapat dilihat pada tabel berikut ini :

Table 5

Kebutuhan Modal Kerja pada PDAM Tirta Mayang Kota Jambi (Rp)

\begin{tabular}{ccccc}
\hline Tahun & $\begin{array}{c}\text { Penjualan Air } \\
(\mathbf{R p})\end{array}$ & $\begin{array}{c}\text { Kecepatan } \\
\text { Perputaran } \\
\text { Modal Kerja } \\
\mathbf{( k a l i )}\end{array}$ & $\begin{array}{c}\text { Kebutuhan Modal } \\
\text { Kerja } \\
\mathbf{( R \mathbf { p } )}\end{array}$ & $\begin{array}{c}\text { Perkembangan } \\
\mathbf{( \% )}\end{array}$ \\
\hline 2013 & 54.862 .430 .120 & 2,44 & $22.484 .602 .508,19$ & - \\
\hline 2014 & 61.356 .783 .650 & 2,13 & $28.806 .001 .713,61$ & 28,11 \\
\hline 2015 & 69.658 .178 .831 & 2,41 & $28.903 .808 .643,57$ & 0,3 \\
\hline 2016 & 71.247 .006 .440 & 1,94 & $36.725 .261 .051,55$ & 27,06 \\
\hline 2017 & 72.834 .205 .583 & 2,27 & $31.386 .346 .449,34$ & $(14,54)$ \\
\hline $\begin{array}{c}\text { Total } \\
\text { Rata-rata }\end{array}$ & $\mathbf{6 5 . 9 9 1 . 7 2 0 . 9 2 4 , 8}$ & $\mathbf{2 , 2 4}$ & $\mathbf{2 3 . 6 6 1 . 2 0 4 . 0 7 3 , 2 5}$ & $\mathbf{8 , 1 8}$ \\
\hline
\end{tabular}

Sumber : Penelitian lapangan Data diolah, 2022

Berdasarkan hasil penyelidikan dan prasyarat modal kerja dari tahun 2013 sampai dengan tahun 2017 PDAM Tirta Mayang Kota Jambi, maka prasyarat modal kerja yang diperlukan pada tahun 2013 adalah sebesar Rp22.484.602.508,19, sedangkan modal kerja yang dapat diakses (sumber daya saat ini pada laporan Aset per 31 Desember 2012) ditambah hingga Rp. 21.049.528.209, menyiratkan bahwa terdapat kekurangan modal kerja yang diharapkan untuk mendukung pelaksanaan fungsional organisasi pada tahun 2013 sebesar Rp. 1.435.074.299,19 atau 6,38\% dari kegiatannya. Pada tahun 2014 prasyarat modal kerja yang diperlukan adalah Rp.28.806.001.713,61, sedangkan modal kerja yang dapat diakses (sumber daya terkini pada laporan Akuntansi per 31 Desember 2013) adalah Rp.23.740.742.311, menyiratkan bahwa ada kekurangan modal kerja yang diharapkan untuk mendanai latihan. kegiatan organisasi pada tahun 2014 mencapai Rp5.065.259.402,61 atau 17,58\% dari tugasnya. Pada tahun 2015 prasyarat modal kerja yang diperlukan adalah sebesar Rp. 28.903.808.643,57, sedangkan modal kerja yang dapat diakses (sumber daya terkini pada Laporan Akuntansi per 31 Desember 2014) adalah sebesar Rp. 29.959.314.854, menyiratkan bahwa ada banyak uang kerja untuk mendanai latihan fungsional organisasi. pada tahun 2015 bertambah menjadi Rp1.055.506.210,43 atau 3,52\% dari tugasnya. Untuk tahun 2016 prasyarat modal kerja yang diperlukan adalah Rp36.725.261.051,55, sedangkan modal kerja yang dapat diakses (sumber daya saat ini pada laporan Aset per 31 Desember 2015) adalah Rp.30.693.673.708, menyiratkan bahwa ada kekurangan modal kerja yang diharapkan untuk mendanai organisasi senam fungsional pada tahun 2014 mencapai 
FINANCE: a Research Journal on Islamic Finance Vol.07 No. 02 Desember 2021 http//jurnal.radenfatah.ac.id/index.php/i-finance Wawan, Dafiar, Rezki dan Mursal.........Perbandingan Kebutuhan Modal Kerja

Rp6.031.587.343,55 atau 16,42\% dari kegiatannya. Terlebih lagi pada tahun 2017 prasyarat modal kerja yang diperlukan adalah Rp. 31.386.346.449,34, sedangkan modal kerja yang dapat diakses (sumber daya terkini pada catatan Moneter per 31 Desember 2016) adalah Rp. 38.894.998.780, yang berarti ada banyak uang kerja untuk mendukung latihan fungsional. organisasi pada tahun 2015 menambahkan hingga Rp7.508.652.330,66 atau $23,92 \%$ dari tugasnya.

Perhitungan Analisis Kebutuhan Modal Kerja pada PDAM Tirta Sakti Kabupaten Kerinci Periode Tahun 2013-2017

Analisis Perputaran Modal Kerja

Analisis perputaran modal kerja pada PDAM Tirta Sakti Kabupaten Kerinci periode tahun 2013 - 2017 dapat dilihat pada tabel 6 berikut:

Table 6.

Penjualan Air, Kas, Piutang, Persediaan PDAM Tirta Sakti Kabupaten Kerinci (Rp)

\begin{tabular}{lrrrrc}
\hline & $\mathbf{2 0 1 3}$ & $\mathbf{2 0 1 4}$ & $\mathbf{2 0 1 5}$ & $\mathbf{2 0 1 6}$ & \multicolumn{2}{c}{$\mathbf{2 0 1 7}$} \\
\hline Penjualan Air & 17.182 .195 .260 & 18.502 .835 .120 & 18.424 .908 .880 & 17.230 .992 .040 & 27.315 .282 .300 \\
\hline $\begin{array}{l}\text { Kas dan Setara } \\
\text { Kas }\end{array}$ & 899.166 .007 & 1.260 .696 .980 & 1.563 .577 .251 & 936.808 .466 & 4.129 .914 .188 \\
\hline Piutang & 3.330 .485 .667 & 2.916 .575 .961 & 3.323 .224 .031 & 4.536 .176 .081 & 5.285 .260 .161 \\
\hline Persediaan & 1.464 .694 .794 & 1.386 .423 .431 & 1.426 .294 .273 & 1.195 .151 .267 & 4.157 .678 .334
\end{tabular}

Sumber : Penelitian lapangan Data diolah, 2022

Berdasarkan table 6 dapat dihitung Perputaran Modal Kerja PDAM Tirta Mayang Kota Jambi dengan hasil perhitungan dari cash turnover, receivable turnover, inventory turnover, dan perputaran modal kerja dapat dilihat pada tabel berikut :

Tabel 7

Kebutuhan Modal Kerja PDAM Tirta Sakti Kabupaten Kerinci

\begin{tabular}{ccccc}
\hline Tahun & $\begin{array}{c}\text { Perputaran } \\
\text { Kas } \\
\text { (hari) }\end{array}$ & $\begin{array}{c}\text { Perputaran } \\
\text { Piutang } \\
\text { (hari) }\end{array}$ & $\begin{array}{c}\text { Perputaran } \\
\text { Persediaan } \\
\text { (hari) }\end{array}$ & $\begin{array}{c}\text { Total Kecepatan } \\
\text { Perputaran Modal } \\
\text { Kerja } \\
\text { (kali) }\end{array}$ \\
\hline 2013 & 18,83 & 69,76 & 30,69 & 3,02 \\
\hline 2014 & 24,53 & 56,78 & 26,98 & 3,32 \\
\hline 2015 & 30,56 & 64,98 & 27,86 & 2,92 \\
\hline 2016 & 19,57 & 94,74 & 24,96 & 2,58 \\
\hline 2017 & 54,46 & 69,63 & 54,79 & 2,01 \\
\hline $\begin{array}{c}\text { Total } \\
\text { Rata-rata }\end{array}$ & $\mathbf{2 9 , 5 9}$ & $\mathbf{7 1 , 1 8}$ & $\mathbf{3 3 , 0 5}$ & $\mathbf{2}$ \\
\hline
\end{tabular}

Sumber : Penelitian lapangan Data diolah, 2022

Terlihat dari tabel 7 di atas bahwa perputaran kas, perputaran uang jatuh tempo, perputaran saham dan kecepatan perputaran modal kerja lengkap selama PDAM Tirta Sakti, Rezim Kerinci, terombang-ambing. Perputaran uang normal adalah 29,59 hari, perputaran piutang tercatat normal adalah 71,18 hari, perputaran stok normal adalah 33,05 hari dan perputaran modal kerja habis-habisan adalah 2,77 kali. Perputaran uang terpanjang pada tahun 2017 adalah 54,46 hari dan tercepat pada tahun 2013 adalah 18,83 hari. Perputaran piutang terlama pada tahun 2016 adalah 94,74 hari dan tercepat pada tahun 2014 adalah 56,78 hari. Perputaran saham terlama pada tahun 2017 adalah 54,79 hari dan 
FINANCE: a Research Journal on Islamic Finance Vol.07 No. 02 Desember 2021 http//jurnal.radenfatah.ac.id/index.php/i-finance

Wawan, Dafiar, Rezki dan Mursal.........Perbandingan Kebutuhan Modal Kerja

tercepat pada tahun 2016 adalah 24,96 hari. Perputaran modal kerja lengkap tertinggi terjadi pada tahun 2014 sebanyak 3,32 kali dan terendah pada tahun 2016 sebanyak 2,01 kali.

\section{Analisis Kebutuhan Modal Kerja}

Analisis kebutuhan modal kerja pada PDAM Tirta Sakti Kabupaten Kerinci periode tahun 2013 - 2017 dapat dilihat pada tabel 6 berikut:

\section{Tabel 8}

Perbandingan Penjualan Air, Kas, Piutang, dan Persediaan (Rp)

\begin{tabular}{lccccc}
\hline & $\mathbf{2 0 1 3}$ & $\mathbf{2 0 1 4}$ & $\mathbf{2 0 1 5}$ & $\mathbf{2 0 1 6}$ & $\mathbf{2 0 1 7}$ \\
\hline Penjualan Air & 17.182 .195 .260 & 18.502 .835 .120 & 18.424 .908 .880 & 17.230 .992 .040 & 27.315 .282 .300 \\
\hline Total & & & & & \\
Kecepatan & 3,02 & 3,32 & 2,92 & 2,58 & 2,01 \\
$\begin{array}{l}\text { Perputaran } \\
\text { Modal kerja }\end{array}$ & & & & & \\
\hline
\end{tabular}

Sumber : Penelitian lapangan Data diolah, 2022

Berdasarkan tabel 8. dihitung Kebutuhan Modal Kerja PDAM Tirta Sakti

Kabupaten Kerinci dengan hasil perhitungan sebagai berikut :

\section{Tabel 9}

Kebutuhan Modal Kerja pada PDAM Tirta Sakti Kabupaten Kerinci (Rp)

\begin{tabular}{ccccc}
\hline Tahun & $\begin{array}{c}\text { Penjualan Air } \\
\text { (Rp) }\end{array}$ & $\begin{array}{c}\text { Total } \\
\text { Kecepatan } \\
\text { Perputaran } \\
\text { Modal Kerja } \\
\text { (kali) }\end{array}$ & $\begin{array}{c}\text { Kebutuhan Modal } \\
\text { Kerja } \\
\text { (Rp) }\end{array}$ & $\begin{array}{c}\text { Perkembangan } \\
\text { (\%) }\end{array}$ \\
\hline 2013 & 17.182 .195 .260 & 3,02 & $5.689 .468 .629,14$ & - \\
\hline 2014 & 18.502 .835 .120 & 3,32 & $5.573 .143 .108,43$ & $(2,04)$ \\
\hline 2015 & 18.424 .908 .880 & 3,32 & $6.309 .900 .301,37$ & 13,22 \\
\hline 2016 & 17.230 .992 .040 & 2,58 & $6.678 .679 .085,27$ & 5,84 \\
\hline 2017 & 27.315 .282 .300 & 2,01 & $13.589 .692 .686,57$ & 103,49 \\
\hline Rata-rata & $\mathbf{1 9 . 7 3 1 . 2 4 2 . 7 2 0}$ & $\mathbf{2 , 8 5}$ & $\mathbf{7 . 5 6 8 . 1 7 6 . 7 6 2 , 1 6}$ & $\mathbf{2 4 , 1 0}$ \\
\hline Sumbr
\end{tabular}

Sumber : Penelitian lapangan Data diolah, 2022

Berdasarkan hasil pemeriksaan dan prasyarat modal kerja 2013-2017 PDAM Tirta

Sakti Rezim Kerinci, maka prasyarat modal kerja yang diperlukan pada tahun 2013 adalah Rp5.689.468.629,14, sedangkan modal kerja yang dapat diakses (sumber daya saat ini pada catatan Moneter per 31 Desember) 2012) bertambah menjadi Rp6.258.853.633, menyiratkan bahwa ada banyak uang kerja untuk mendukung latihan fungsional organisasi pada tahun 2013 sebesar Rp. 569.385.003,86 atau 10\% dari tugasnya. Pada tahun 2014 prasyarat modal kerja yang diperlukan adalah Rp5.573.143.108,43, sedangkan modal kerja yang dapat diakses (sumber daya saat ini pada laporan Aset per 31 Desember 2013) adalah Rp7.148.591.811,79, menyiratkan bahwa ada banyak arus kas kerja untuk mendanai latihan kegiatan organisasi pada tahun 2013 mencapai Rp. 1.575.448.703,36 atau 28,27\% dari kegiatannya. Pada tahun 2015 prasyarat modal kerja yang diperlukan adalah sebesar Rp. 6.309.900.301,37, sedangkan modal kerja yang dapat diakses (sumber daya saat ini pada laporan Aset per 31 Desember 2014) bertambah menjadi Rp7.027.667.549.,25, menyiratkan bahwa ada arus kas kerja yang melimpah untuk mendukung kegiatan organisasi di tahun 2015 ditambah sampai dengan Rp717.767.247,88 atau 11,37\% dari tugasnya. Untuk tahun 2016 prasyarat modal kerja yang diperlukan adalah Rp. 6.678.679.085,27, sedangkan modal 
FINANCE: a Research Journal on Islamic Finance Vol.07 No. 02 Desember 2021 http//jurnal.radenfatah.ac.id/index.php/i-finance

Wawan, Dafiar, Rezki dan Mursal.........Perbandingan Kebutuhan Modal Kerja

kerja yang dapat diakses (sumber daya terkini pada laporan Aset per 31 Desember 2015) adalah Rp. 7.853.727.565,36, menyiratkan bahwa ada banyak uang kerja untuk mendukung latihan fungsional organisasi pada tahun 2016 ditambah dengan Rp1.175.048.480,09 atau 17,59\% dari kegiatannya. Selanjutnya pada tahun 2017 prasyarat modal kerja yang diperlukan adalah sebesar Rp. 13.589.692.686,57, sedangkan modal kerja yang dapat diakses (sumber daya terkini pada Catatan Moneter per 31 Desember 2016) adalah Rp. 8.282.065.324 yang berarti terdapat kekurangan modal kerja yang diharapkan untuk mendanai latihan fungsional organisasi pada tahun 2015 ditambah sebesar Rp5.307.627.362,57 atau 39,05\% dari tugasnya.

Berdasarkan hasil analisis kebutuhan modal kerja PDAM Tirta Mayang Kota Jambi dan PDAM Tirta Sakti Kabupaten Kerinci terlihat bahwa kondisi yang cenderung meningkat terhadap kebutuhan modal kerja pada kedua perusahaan tersebut pada periode 2013-2017. Dimana untuk PDAM Kota Jambi pada tahun 2014 mengalami peningkatan tertinggi sebesar 28,11\% dan pada tahun 2017 mengalami penurunan sebesar 14,54\%, dengan rata-rata sebesar 8,18\%. Dan untuk Kebutuhan modal kerja PDAM Tirta Sakti Kabupaten Kerinci juga mengalami fluktuasi yang cenderung meningkat dimana pada tahun 2017 mengalami peningkatan tertinggi sebesar 103,49\% dan pada tahun 2014 turun sebesar 2,04\%, dengan rata-rata sebesar 24,10\%. Besaran kebutuhan modal kerja untuk PDAM Kota Jambi jauh lebih besar dibandingkan PDAM Kabupaten Kerinci pada periode 20132017 dimana rata-rata kebutuhan modal kerja untuk PDAM Kota jambi adalah sebesar Rp23.661.204.073,25 dan Rp7.568.176.762,16 untuk PDAM Kabupaten Kerinci.

\section{Perbandingan Kebutuhan Modal Kerja Antara PDAM Kota jambi dan PDAM Kabupaten Kerinci}

Tabel 10

Hasil uji normalitas dapat dilihat pada tabel 10 berikut ini:

Tests of Normality

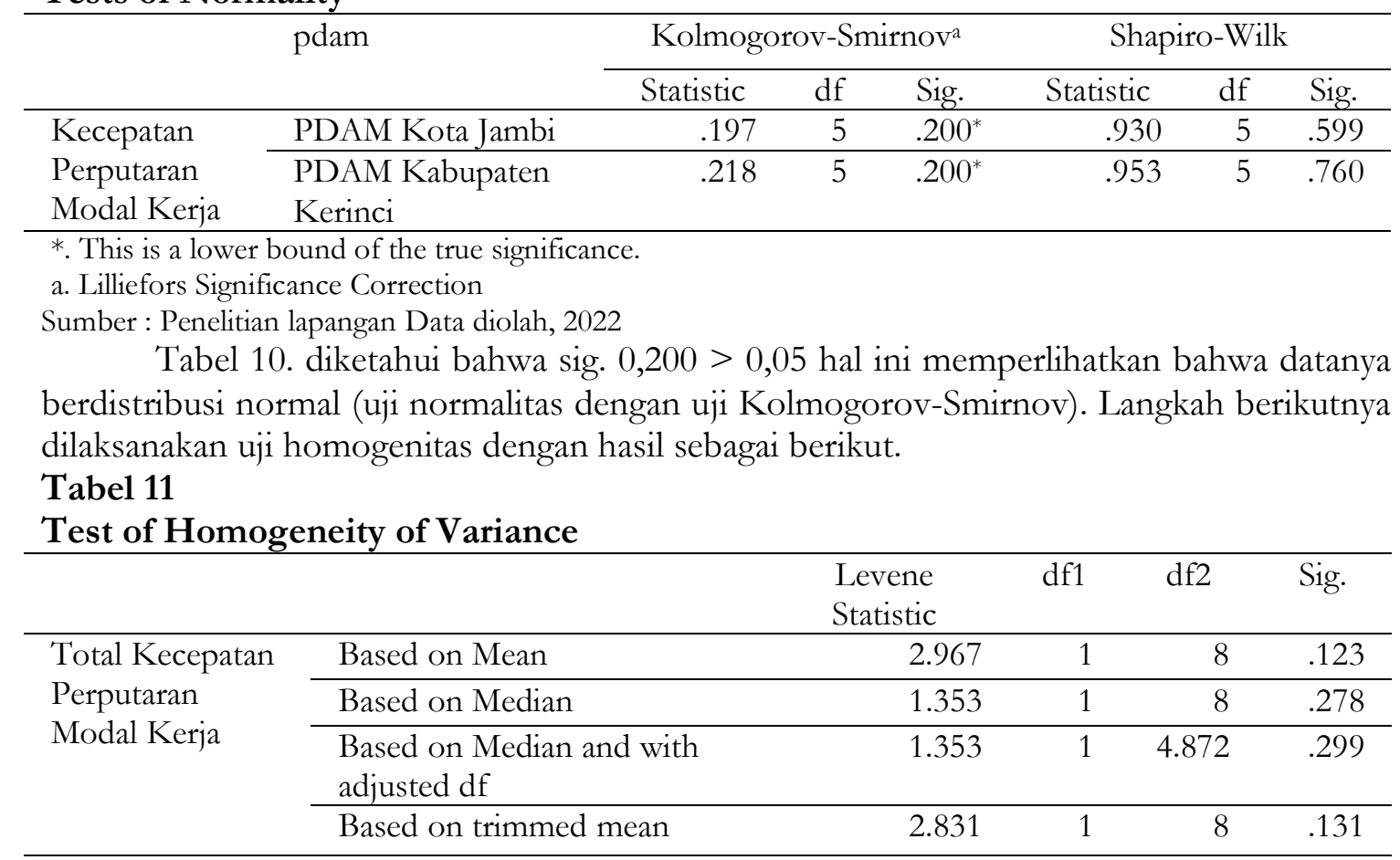

Sumber : Penelitian lapangan Data diolah, 2022 
FINANCE: a Research Journal on Islamic Finance Vol.07 No. 02 Desember 2021 http//jurnal.radenfatah.ac.id/index.php/i-finance

Wawan, Dafiar, Rezki dan Mursal.........Perbandingan Kebutuhan Modal Kerja

Dari hasil uji homogenitas pada table 11. diketahui nilai Sig. 0,123>0,05 maka data berdistribusi homogen (uji homogenitas dengan uji Levene).

Langkah selanjutnya untuk mengetahui perbandingan kebutuhan modal kerja antara PDAM Tirta Mayang Jambi dan PDAM Tirta Sakti Kabupaten Kerinci dilakukan dengan pengujian independent sample t-test dengan hasil sebagai berikut:

\section{Tabel 12}

\section{Uji Independent sample $t$ test}

\begin{tabular}{|c|c|c|c|c|}
\hline & & & \multicolumn{2}{|c|}{$\begin{array}{l}\text { Total Kecepatan Perputaran } \\
\text { Modal Kerja }\end{array}$} \\
\hline & & & $\begin{array}{c}\text { Equal } \\
\text { variances } \\
\text { assumed }\end{array}$ & $\begin{array}{c}\text { Equal variances } \\
\text { not assumed }\end{array}$ \\
\hline \multirow{2}{*}{$\begin{array}{l}\text { Levene's Test for } \\
\text { Equality of } \\
\text { Variances }\end{array}$} & F & & 2.967 & \\
\hline & Sig. & & .123 & \\
\hline \multirow{7}{*}{$\begin{array}{l}\text { t-test for Equality } \\
\text { of Means }\end{array}$} & $\mathrm{t}$ & & -2.197 & -2.197 \\
\hline & df & & 8 & 5.334 \\
\hline & Sig. (2-tailed) & & .059 & .076 \\
\hline & Mean Difference & & -.53200 & -.53200 \\
\hline & Std. Error Differ & & .24219 & .24219 \\
\hline & $95 \%$ Confidence & Lower & -1.09048 & -1.14301 \\
\hline & $\begin{array}{l}\text { Interval of the } \\
\text { Difference }\end{array}$ & Upper & .02648 & .07901 \\
\hline
\end{tabular}

Berdasarkan Tabel 12. oleh karena hasil menunjukkan data yang homogen maka diketahui nilai signifikansi untuk equal variance assumed sebesar 0,059 >0,05 yang berarti tidak terdapat perbedaan yang signifikan kebutuhan modal kerja antara PDAM Tirta Mayang Jambi dan PDAM Tirta Sakti Kab. Kerinci ataupun perusahaan PDAM Tirta Mayang Kota Jambi.

\section{Pembahasan}

Nilai signifikansi untuk equal variance assumed sebesar 0,059 > 0,05 yang berarti tidak ada perbedaan yang signifikan kebutuhan modal kerja antara PDAM Tirta Mayang Jambi dan PDAM Tirta Sakti Kab. Kerinci ataupun perusahaan PDAM Tirta Mayang Kota Jambi.

Mengingat efek samping dari penyelidikan dan prasyarat modal kerja dari tahun 2013 hingga tahun 2017 PDAM Tirta Mayang Kota Jambi, maka kebutuhan modal kerja yang diharapkan pada tahun 2013 adalah sebesar Rp. 2012) ditambah hingga Rp. 21.049.528.209, dimaksudkan adanya kekurangan modal kerja diharapkan dapat mendukung pelaksanaan fungsional organisasi tahun 2013 sebesar Rp. 1.435.074.299,19 atau 6,38\% dari kegiatannya. Pada tahun 2014 kebutuhan modal kerja yang diperlukan adalah sebesar Rp28.806.001.713,61, sedangkan modal kerja yang dapat diakses (sumber daya saat ini pada catatan Moneter per 31 Desember 2013) adalah sebesar Rp.23.740.742.311, hal ini dimaksudkan agar terjadi kekurangan modal kerja yang diharapkan latihan punggung. kegiatan organisasi pada tahun 2014 mencapai Rp5.065.259.402,61 atau 17,58\% dari tugasnya. Pada tahun 2015 prasyarat modal kerja yang diperlukan adalah Rp.28.903.808.643,57, sedangkan modal kerja yang dapat diakses (sumber daya saat ini dalam catatan Moneter per 31 Desember 2014) adalah Rp.29.959.314.854, benar-benar bertujuan agar ada arus kas kerja yang melimpah untuk 
FINANCE: a Research Journal on Islamic Finance Vol.07 No. 02 Desember 2021 http//jurnal.radenfatah.ac.id/index.php/i-finance

Wawan, Dafiar, Rezki dan Mursal.........Perbandingan Kebutuhan Modal Kerja

kembali latihan fungsional organisasi. pada tahun 2015 menambahkan hingga Rp1.055.506.210,43 atau 3,52\% dari aktivitasnya. Untuk tahun 2016 prasyarat modal kerja yang diperlukan adalah sebesar Rp36.725.261.051,55, sedangkan modal kerja yang dapat diakses (sumber-sumber terkini pada Laporan Akuntansi per 31 Desember 2015) adalah Rp.30.693.673.708, dengan maksud agar tidak terjadi kekurangan modal kerja yang diharapkan untuk mendanai pelaksanaan fungsional organisasi pada tahun 2014 mencapai Rp6.031.587.343,55 atau 16,42\% dari tugasnya. Selanjutnya pada tahun 2017 prasyarat modal kerja yang diperlukan adalah sebesar Rp. 31.386.346.449.34, sedangkan modal kerja yang dapat diakses (sumber daya terkini pada Catatan Moneter per 31 Desember 2016) adalah Rp. 38.894.998.780, pentingnya ada banyak uang bekerja untuk mendukung latihan fungsional. organisasi pada tahun 2015 menambahkan hingga Rp7.508.652.330,66 atau $23,92 \%$ dari tugasnya.

Sementara itu, dari hasil pemeriksaan dan prasyarat modal kerja tahun 2013 hingga 2017 PDAM Tirta Sakti Rezim Kerinci memperoleh kebutuhan modal kerja yang diperlukan pada tahun 2013 bertambah menjadi Rp. 5.689.468.629,14, sedangkan modal kerja yang dapat diakses (sumber-sumber terkini pada Laporan Akuntansi per 31 Desember 2012) bertambah menjadi Rp6.258.853.633, dengan maksud agar ada dana kerja yang melimpah untuk mendukung pelaksanaan fungsional organisasi di tahun 2013 menjadi Rp569.385.003,86 atau 10\% dari kegiatannya. Pada tahun 2014 prasyarat modal kerja yang diperlukan adalah sebesar Rp5.573.143.108,43, sedangkan modal kerja yang dapat diakses (sumber daya saat ini pada laporan Aset per 31 Desember 2013) adalah sebesar Rp7.148.591.811,79, sebenarnya dimaksudkan agar terjadi kelebihan dana kerja untuk mendukung pelaksanaan kegiatan tersebut. tugas organisasi pada tahun 2013 bertambah menjadi Rp. 1.575.448.703,36 atau 28,27\% dari tugasnya. Pada tahun 2015 prasyarat modal kerja yang diharapkan adalah sebesar Rp. 6.309.900.301,37, sedangkan modal kerja yang dapat diakses (sumber daya terkini dalam catatan Moneter per 31 Desember 2014 ) bertambah menjadi Rp7.027.667.549.,25, dengan maksud bahwa ada banyak dana kerja untuk mendukung tugas organisasi di tahun 2015 bertambah menjadi Rp717.767.247,88 atau $11,37 \%$ dari kegiatannya. Untuk tahun 2016 prasyarat modal kerja yang diperlukan adalah sebesar Rp. 6.678.679.085,27, sedangkan modal kerja yang dapat diakses (sumber daya terkini pada catatan Moneter per 31 Desember 2015) adalah Rp. 7.853.727.565,36, memaksudkan adanya dana kerja yang melimpah untuk mendukung pelaksanaan fungsional organisasi pada tahun 2016 ditambah dengan Rp1.175.048.480,09 atau 17,59\% dari tugasnya. Selanjutnya pada tahun 2017 prasyarat modal kerja yang diperlukan adalah sebesar Rp. 13.589.692.686,57, sedangkan modal kerja yang dapat diakses (sumber daya terkini pada Catatan Moneter per 31 Desember 2016) adalah Rp. 8.282.065.324, artinya terdapat kekurangan modal kerja yang diharapkan untuk mendanai latihan fungsional organisasi pada tahun 2015 ditambah sebesar Rp5.307.627.362,57 atau 39,05\% dari tugasnya.

Kebutuhan modal kerja pada PDAM Tirta Mayang Kota Jambi dan PDAM Tirta Sakti Kab. Kerinci telah terombang-ambing dalam perjalanan 5 tahun terakhir. Alasan tidak adanya kebutuhan modal kerja adalah karena aset fungsional yang tersedia dalam organisasi tidak memadai untuk mendukung kebutuhan modal berfungsi yang seharusnya.

Hasil penelitian ini mendukung hasil penelitian sebelumnya oleh Sella Machmud, Sri Murni Rustandi, Maryam Mangantar (2015) yang menunjukkan bahwa tidak ada perbedaan perputaran modal kerja antara organisasi modern Food and Refreshment yang tercatat di Bursa Efek Indonesia. 
FINANCE: a Research Journal on Islamic Finance Vol.07 No. 02 Desember 2021 http//jurnal.radenfatah.ac.id/index.php/i-finance

Wawan, Dafiar, Rezki dan Mursal Perbandingan Kebutuhan Modal Kerja

\section{KESIMPULAN}

Nilai signifikansi untuk equal variance assumed sebesar 0,059 > 0,05 yang berarti tidak ada perbedaan yang tidak signifikan kebutuhan modal kerja antara PDAM Tirta Mayang Jambi dan PDAM Tirta Sakti Kab. Kerinci ataupun perusahaan PDAM Tirta Mayang Jambi. Besaran kebutuhan modal kerja untuk PDAM Kota Jambi jauh lebih besar dibandingkan PDAM Kab. Kerinci pada periode 2013-2017 dimana rata-rata kebutuhan modal kerja untuk PDAM Kota jambi adalah sebesar Rp23.661.204.073,25 dan Rp7.568.176.762,16 untuk PDAM Kabupaten Kerinci.

\section{REFERENCES}

Andries, Yudi Afriana. 2011. "Analisis Kinerja Perusahaan Daerah Air Minum (PDAM) Kabuapaten Brebes."

Aprilini, Ranieta, Dwi Risma Deviyanti, and Ledy Setiawati. 2019. "Analisis Kebutuhan Modal Kerja." Jurnal Ilmu Akuntansi Mulawarman (JLAM) 3(2).

Asi Armalaila, Asi. 2019. "ANALISIS KEBUTUHAN MODAL KERJA PADA CV. TASHINDA PUTRAPRIMA YOGYAKARTA."

Aulia, Lily. 2020. "Analisis Kebutuhan Modal Kerja Pada PT. Provident Agro Tbk Tahun 2017-2019."

Efa, Hidayah. 2018. "Analisis Kebutuhan Modal Kerja PT. BISI International Tbk Periode 2015-2017 Dan Proyeksi Kebutuhan Modal Kerja Tahun 2018."

Fahmi, Irham. 2014. "Analisis Kinerja Keuangan. Cetakan Kesatu."

Firdaus, M. Ahlal, and Irwan Taufiq Ritonga. 2018. "Analisis Artikulasi Laporan Keuangan Pemerintah Daerah.” Jurnal Akuntansi Dan Akuntabilitas Publik 1(1):68-87.

Hakim, Yundi Permadi, and Santi Mulyani. 2017. "Analisis Kebutuhan Modal Kerja Pada Rumah Makan Bintang Lima Di Samarinda." Jurnal Ekonomi Dan Manajemen 11(2):270-83.

HUTAM, WILDAN PERWIRA. 2017. "ANALISIS KEBUTUHAN MODAL KERJA (STUDI KASUS PERTAMINA LUBRICANTS THAILAND).”

Idris, Muh, and Seri Suriyani. n.d. "ANALISIS KEBUTUHAN MODAL KERJA TERHADAP PEROLEHAN LABA PADA PT. PERKEBUNAN NUSANTARA XIV (PERSERO) BONE."

Imam, Rangga Tsabit, Siti Masyithoh, and Indra Suyoto Kurniawan. 2018. "Analisis Kebutuhan Modal Kerja Pada Perusahaan Taufik Jaya Makmur Di Samarinda." Jurnal Ilmu Akuntansi Mulawarman (IIAM) 2(4).

Kasmir. 2016. Analisis Laporan Kenangan. Jakarta: PT. Raja Grafindo Persada.

Lahjie, Annisa Abubakar. 2020. "Analisis Kebutuhan Modal Kerja Pada Pdam Tirta Kencana Di Kota Samarinda." Jurnal Ilmu Akuntansi Mulawarman (JLAM) 4(2).

Mendai, Aprilnindia. 2018. "ANALISIS KEBUTUHAN MODAL KERJA PADA TOKO BAGAYA BARBERSHOP POSO.”

MERINA, SEPTA, Mohamad Adam, and Isni Andriana. 2007. "ANALISIS KEBUTUHAN MODAL KERJA PADA PT. INDOFOOD SUKSES MAKMUR, TBK."

Munawir. 2014. Analisa Laporan Kenangan Edisi 4. 4th ed. yogyakarta: Liberty.

Murniati, Sitti. 2016. "ANALISIS KEBUTUHAN MODAL KERJA PADA CV. 
FINANCE: a Research Journal on Islamic Finance Vol.07 No. 02 Desember 2021 http//jurnal.radenfatah.ac.id/index.php/i-finance

Wawan, Dafiar, Rezki dan Mursal Perbandingan Kebutuhan Modal Kerja

BINTANG TIMUR JAYA DI MAKASSAR.” AKMEN Jurnal Imiah 13(4).

Novianti, Cici. 2019. "ANALISIS KEBUTUHAN MODAL KERJA PADA PDAM KABUPATEN POSO."

Resnawati, Ria. 2015. "Analisis Kebutuhan Modal Kerja Dalam Menghasilkan Laba Perusahaan Pada PT Sinar Terang Mulia Kota Tarakan."

Sabran, Sabran. 2017. "Analisis Kebutuhan Modal Kerja Padatoko Bangunan Sukarame Di Tenggarong." Jurnal Ekonomi \& Manajemen Indonesia 17(1).

Sriwati, Ni Kadek. 2013. "ANALISIS KEBUTUHAN MODAL KERJA PADA USAHA TAMBAK IKAN BANDENG DI DESA BEGA KECAMATAN POSO PESISIR.” Ekomen 13(01).

Standar Akuntansi Nasional. 2015. "Komponen-Komponen Laporan Rugi Laba Komperhensif."

Sugiyono, Dr. 2013. "Metode Penelitian Pendidikan Pendekatan Kuantitatif, Kualitatif Dan R\&D."

Suryani, Arna. 2016. "Analisis Kebutuhan Modal Kerja Pada Pdam Tirta Mayang Kota Jambi Periode 2011-2015." Jurnal Imiah Universitas Batanghari Jambi 16(3):130-38.

Syafitri, Yancik. 2013. "EVALUASI TINGKAT KESEHATAN KINERJA KEUANGAN PADA PERUSAHAAN DAERAH AIR MINUM (PDAM) KOTA PALEMBANG." JURNAL KOMPETITIF 2(1).

Timbul, Yuandi K. 2013. "Perputaran Modal Kerja Dalam Mengukur Tingkat Profitabilitas Pada PT. Jasa Angkasa Semesta, Tbk. Jakarta.” Jurnal EMBA: Jurnal Riset Ekonomi, Manajemen, Bisnis Dan Akuntansi 1(4).

Vitasari, Siskha. 2016. “ANALISIS KEBUTUHAN MODAL KERJA UNTUK MENENTUKAN MODAL KERJA OPTIMAL PADA KOPERASI UNIT DESA PAKIS KABUPATEN MALANG."

Widodo, Wahid Ari, and Titin Ruliana. 2020. "ANALISIS KEBUTUHAN MODAL KERJA PADA PT. TRIWISNNA DI KABUPATEN KUTAI TIMUR.” EKONOMLA 9(2):79-91.

Yasha, Ade Fitri. 2017. "Analisis Kebutuhan Modal Kerja Petani Padi Sawah (Studi Kasus: Desa Pematang Setrak, Kecamatan Teluk Mengkudu, Kabupaten Serdang Bedagai).”

Yogatama Baskara, Yogatama. 2019. "ANALISIS KEBUTUHAN MODAL KERJA PADA PT PRIMISSIMA (PERSERO).”

Yuliana, Irma, Iskandar Iskandar, and Dhina Mustika Sari. 2019. "Analisis Kebutuhan Modal Kerja Pada Cv Yola Intan Mandiri Di Bontang." Jurnal Ilmu Akuntansi Mulawarman (ILAM) 3(4).

Zulkifli, Zulkifli. 2013. "Analisis Kebutuhan Modal Kerja Pada CV. Karya Makmur Di Kota Samarinda." Ekonomia 2(1):11-15. 